\title{
Comparison of Protein Profiles in Sputum between COPD and Acute Exacerbation of COPD
}

\author{
Soo-Taek Uh ${ }^{1}$, Seung Ah Ko ${ }^{1}$, An Soo Jang ${ }^{2}$, Sung Woo Park ${ }^{2}$, Yong-Hoon Kim ${ }^{3}$, \\ Young-Ki Paik ${ }^{4}$, Choon Sik Park ${ }^{2 *}$ \\ ${ }^{1}$ Division of Respiratory and Allergy Medicine, Soonchunhyang University Hospital, \\ Seoul, South Korea \\ ${ }^{2}$ Genome Research Center for Allergy and Respiratory Disease, Soonchunhyang University Bucheon Hospital, \\ Bucheon, South Korea \\ ${ }^{3}$ Division of Respiratory Medicine, Soonchunhyang University, Chunan Hospital, Asan, South Korea \\ ${ }^{4}$ Yonsei Proteome Research Center, Department of Biochemistry and Biomedical Science, College of Life Science and \\ Biotechnology, Yonsei University, Seoul, South Korea \\ Email: uhs@schmc.ac.kr, ${ }^{2}$ mdcspark@unitel.co.kr
}

Received January 25, 2012; revised March 7, 2012; accepted March 15, 2012

\begin{abstract}
Background and Objective: Chronic obstructive pulmonary disease (COPD) is characterized by progressive airflow limitation that is associated with an abnormal inflammatory response of the lung to noxious particles or gases. Cigarette smoking is the major risk factor for the development of COPD. This study evaluated the levels of cyclophilin B in sputa from patients with COPD and COPD with acute exacerbation (AECOPD). Materials and Methods: Two-dimensional electrophoresis was used for differential display proteomics. Western blotting was used to identify and quantify cyclophilin B in sputum from subjects with AECOPD and COPD. Results: Forty-nine protein spots differed in relative intensity between the AECOPD $(n=6)$ and COPD $(n=6)$ subjects. Twenty proteins showed increased expression in the sputum of AECOPD subjects, and 29 proteins were present at lower levels in AECOPD sputum compared with COPD sputum. One of these proteins was associated with cyclophilin B. Cyclophilin B concentrations were lower in sputum from subjects with COPD $(n=4)$ versus $\operatorname{AECOPD}(n=4)$. Conclusion: The sputum proteomic analysis suggests that changes in various proteins are associated with the development of AECOPD.
\end{abstract}

Keywords: Proteomics; COPD; Acute Exacerbation; Chromatography, Liquid; Mass Spectrometry

\section{Introduction}

Chronic obstructive pulmonary disease (COPD) is characterized by slowly progressive airway limitation due to abnormal pulmonary inflammatory reactions [1]. The incidence of COPD has been increasing in recent decades, and it is projected to rank third as the cause of death by 2020 [2]. Of the Korean population older than 45 years, $17.2 \%$ have airway obstruction in which the forced expiratory volume in one second $\left(\mathrm{FEV}_{1}\right)$ /forced vital capacity (FVC) ratio is $<0.7$, emphasizing the clinical implications of COPD [3]. A cross-sectional study reported that the mortality rate increased to $2.5 \%$ in COPD patients with acute exacerbation (AECOPD) [4], and acute exacerbation can reduce the long-term survival of patients with COPD $[5,6]$.

Therefore, it is important to identify a marker of AECOPD in order to detect and treat exacerbations early.

${ }^{*}$ Corresponding author.
Markers such as serum surfactant protein D have been evaluated in patients with AECOPD, but no one marker can distinguish between COPD and AECOPD [7,8]. The identification of respiratory disease-specific proteins in the airway and alveolar lining fluids will help to improve the early detection, prognosis, and treatment of these diseases. Therefore, large-scale, high-throughput, wholeproteome studies of bronchoalveolar lavage (BAL) fluids using two-dimensional electrophoresis (2DE) and matrix-assisted laser desorption/ionization time-of-flight (MALDI-ToF) mass spectroscopy (MS) have been conducted to determine the proteomic contribution to asthma and idiopathic pulmonary fibrosis $[9,10]$.

\section{Materials and Methods}

\subsection{Patients and Sputum Collection}

Six patients with AECOPD were enrolled in this study. The diagnostic criteria for COPD were as follows: 1) post-bronchodilator $\mathrm{FEV}_{1} / \mathrm{FVC}$ ratio $<70 \%$ [1]; 2) smok- 
ing for more than 10 pack-years; and 3) no abnormal findings of obstructive airway disease such as advanced inactive tuberculosis or severe bronchiectasis on chest X-rays. A bronchodilator test was performed before and 6 weeks after an acute exacerbation. AECOPD was defined as an event in the natural course of the disease characterized by a change in the patient's baseline dyspnea, cough, or sputum that was beyond the normal day-to-day variation, was acute in onset, and warranted a change in regular medication in a patient with underlying COPD [1]. Sputum was collected on the first day of an acute exacerbation and $6-7$ weeks after the acute exacerbation. The patients' clinical characteristics are summarized in Table 1.

The study was approved by the ethics committee, and all subjects provided informed consent.

\subsection{Sputum Preparation}

All visibly more-solid portions of the sputum were selected carefully and placed in a preweighed Eppendorf tube, to which four volumes of $0.1 \%$ dithiothreitol (Sputolysin; Calbiochem, San Diego, CA, USA) was added. One volume of protease inhibitors (0.1 M EDTA and 2 $\mathrm{mg} / \mathrm{ml}$ phenylmethylsulfonyl fluoride) was added to 100 volumes of the homogenized sputum, and the total cell count was determined with a hemocytometer. The homogenized sputum was spun in a cytocentrifuge, and 500 cells were examined on each sputum slide stained with Diff-Quik solution (American Scientific Products, Chicago, IL, USA). The homogenized sputum sample was centrifuged at $1000 \times \mathrm{g}$ for $5 \mathrm{~min}$, and the supernatant was collected and stored at $-70^{\circ} \mathrm{C}$ for subsequent analy- sis. Bacterial cultures and tests to detect rhinoviruses were performed in cases of exacerbated COPD. A pharyngeal swab was obtained and inoculated onto cell monolayers to isolate influenza A and B; parainfluenza 1, 2, and 3 ; adenovirus; and respiratory syncytial virus. Human rhinoviruses were detected using reverse transcriptase-polymerase chain reaction with rhinovirus-specific primers.

\subsection{Sample Preparation, Two-Dimensional Electrophoresis, and Image Analysis}

Sputum samples containing $200 \mu \mathrm{g}$ of protein from each patient were pooled for the two-dimensional analysis. One milligram of protein from the pooled sputum was precipitated with $10 \%$ trichloroacetic acid in acetone and resuspended in the sample solution. Immobiline Dry Strips (Amersham Biosciences) were used for isoelectric focusing (IEF), which was performed with $1 \mathrm{mg}$ of the extracted protein on a Multiphor II $^{\mathrm{TM}}$ electrophoresis system (GE Healthcare). After IEF separation, the proteins were separated in the second dimension by sodium dodecyl sulfate-polyacrylamide gel electrophoresis (SDSPAGE). For image analysis, the gels were visualized with Coomassie Brilliant Blue G-250 according to the manufacturer's instructions. The 2D gels were scanned by an ImageScanner (Bio-Rad) in transmission mode. Spot detection and matching were performed using ImageMaster 2D version 5.0 (Amersham Biosciences). Digitized images were analyzed using the program ImageMaster to calculate each 2D spot intensity by integrating the optical density over the spot area (the spot "volume"), followed by normalization [11].

Table 1. Clinical characteristics of patients.

\begin{tabular}{|c|c|c|c|c|c|c|c|c|c|c|c|c|c|}
\hline & \multirow{2}{*}{ Age/Sex } & \multirow{2}{*}{$\mathrm{PY}^{*}$} & \multirow{2}{*}{$\mathrm{FEV}_{1} \mathrm{~L} / \%$ pred. } & \multirow{2}{*}{$\begin{array}{c}\text { Cause of } \\
\text { exacerbation }\end{array}$} & \multirow{2}{*}{ Virus } & \multirow{2}{*}{ Bacteria } & \multicolumn{3}{|c|}{ Ex-Sputum cell count } & \multicolumn{3}{|c|}{ St-Sputum cell count } & \multirow{2}{*}{ Treatment } \\
\hline & & & & & & & Total & $\mathrm{M}(\%)$ & $\mathrm{N}(\%)$ & Total & $\mathrm{M}(\%)$ & $\mathrm{N}(\%)$ & \\
\hline 1 & $82 / \mathrm{M}$ & 60 & $1.60 \mathrm{~L} / 89$ & Pneumonia & ND & $\begin{array}{l}\text { Pseudomonas } \\
\text { fluorescensputida }\end{array}$ & 14 & 1 & 99 & 55 & 8 & 92 & $\begin{aligned} & \mathrm{SS}+\mathrm{SABA} \\
+ & \mathrm{SAMA}+\text { Anti }\end{aligned}$ \\
\hline 2 & $82 / \mathrm{M}$ & 35 & $1.53 \mathrm{~L} / 72$ & Pneumonia & ND & Micrococcus species & 12 & 2 & 89 & 1 & 2 & 86 & $\begin{array}{l}\mathrm{SS}+\mathrm{SABA} \\
+ \text { Anti }\end{array}$ \\
\hline 3 & $68 / \mathrm{M}$ & 60 & $0.89 \mathrm{~L} / 39$ & Pneumonia & ND & ND & 2 & 2 & 91 & 12 & 43 & 35 & $\begin{array}{l}\mathrm{SS}+\mathrm{SABA} \\
+ \text { Anti }\end{array}$ \\
\hline 4 & $78 / \mathrm{M}$ & 50 & $1.00 \mathrm{~L} / 38$ & Unknown & ND & ND & 190 & 1 & 99 & 9 & 3 & 96 & $\begin{array}{c}\text { SS + LAMA } \\
+ \text { SAMA + } \\
\text { SABA }\end{array}$ \\
\hline 5 & $63 / \mathrm{M}$ & 90 & $1.47 \mathrm{~L} / 56$ & Pneumonia & ND & $\begin{array}{l}\text { Staphylococcus } \\
\text { capitis }\end{array}$ & 18 & 5 & 89 & 10 & 40 & 56 & $\begin{array}{l}\mathrm{SS}+\mathrm{SABA} \\
+ \text { Anti }\end{array}$ \\
\hline 6 & $56 / \mathrm{M}$ & 20 & $2.89 \mathrm{~L} / 80$ & Pneumonia & ND & Subspecies capitis & 45 & 7 & 78 & 4.8 & 60 & 24 & $\begin{array}{l}\mathrm{SS}+\mathrm{SABA} \\
+ \text { Anti }\end{array}$ \\
\hline
\end{tabular}

Definition of abbreviations: PY: Smoking, pack-years; $\mathrm{FEV}_{1}$ : Forced expiratory volume in 1 second. This value was the most recent data before exacerbation; \% pred: \% predicted; Ex-Sputum cell count: Sputum cell count during exacerbation state; St-Sputum cell count: Sputum cell count during stable state; Total: Total cell count, $\times 10^{5} / \mathrm{mL}$; M: Macrophage; N: Neutrophil; ND: Not-detected; SS: Systemic steroid; SABA: Short acting beta-2 agonist; SAMA: Short acitng muscarinic antagonist; Anti: Antibiotics; LAMA: Long acting muscarinic antagonist. 


\subsection{Protein Identification by Nano-LC-MS/MS and Database Searching}

Differentially expressed protein spots were excised from the 2D gels, cut into smaller pieces, and digested with trypsin (Promega), as described previously [12]. All LC-MS/MS experiments were performed using Agilent Nanoflow Proteomics Solution with an Agilent 1100 Series nano-LC system. For MS/MS, this was coupled through an orthogonal nanospray ion source to an Agilent 1100 Series LC/MSD Trap XCT ion trap mass spectrometer.

The nano-LC system was operated in sample enrichment/desalting mode with a Zorbax 300SB-C18 enrichment column $(0.3 \times 50 \mathrm{~mm}, 5 \mu \mathrm{m})$. Chromatography was performed using a Zorbax 300SB-C18 $(75 \mu \mathrm{m} \times 150 \mathrm{~mm})$ nanocolumn. The column was eluted with a gradient beginning with isocratic application of $3 \%$ solvent B $(0.1 \%$ formic acid in acetonitrile) and 97\% solvent A (0.1\% formic acid in water) for $5 \mathrm{~min}$ and changing to $10 \% \mathrm{~B}$ over $5 \mathrm{~min}$ (from 5 to $10 \mathrm{~min}$ ), to $45 \% \mathrm{~B}$ over $40 \mathrm{~min}$ (10 - $50 \mathrm{~min}$ ), to $90 \% \mathrm{~B}$ (isocratic) for $5 \mathrm{~min}$ (55 - $60 \mathrm{~min}$ ), and to $3 \% \mathrm{~B}$ over $1 \mathrm{~min}(60-61 \mathrm{~min})$. Finally, the column was washed with $3 \% \mathrm{~B}$ for $10 \mathrm{~min}$.

The LC/MSD Trap XCT was operated in unique peptide scan Auto-MS/MS mode. The ionization mode was positive nanoelectrospray with an Agilent orthogonal source. The drying gas flowed at $5 \mathrm{~L} / \mathrm{min}$ at a temperature of $300^{\circ} \mathrm{C}$. $\mathrm{V}_{\text {cap }}$ was typically $1800-1900 \mathrm{~V}$ with skim 1 at $30 \mathrm{~V}$, and the capillary exit was offset at $75 \mathrm{~V}$. The trap drive was set at $85 \mathrm{~V}$ with averages of one or two. The ion charge control was on with a maximum accumulation time of $150 \mathrm{~ms}$, the smart target was 125,000 , and the MS scan range was 300 - 2200. Automatic MS/MS was performed in ultrascan mode with the number of parents at 2, averages of two fragmentation amplitude of $1.15 \mathrm{~V}$, SmartFrag on (30\% - 200\%), active exclusion on (after-two spectra for $1 \mathrm{~min}$ ), prefer +2 on, MS/MS scan range of 100 - 1800, and ultrascan on. Each acquired MS/MS spectrum was searched against the non-redundant protein sequence database using Spectrum Mill software [12].

\subsection{Detecting Cyclophilin B in Sputum by Western Blotting}

First, $200 \mu \mathrm{g}$ of protein were electrophoresed in a $15 \%$ polyacrylamide gel with a discontinuous system. The proteins were transferred to a nitrocellulose membrane at $120 \mathrm{~V}$ for $40 \mathrm{~min}$. The membrane was blocked with 5\% skim milk and $0.1 \%$ NP40 in Tris-buffered saline for $2 \mathrm{~h}$ at room temperature, and incubated overnight with a 1:500 dilution of rabbit polyclonal antibody against cyclophilin $\mathrm{B}$ at $4^{\circ} \mathrm{C}$. The membrane was incubated with horseradish peroxidase (HRP)-conjugated anti-rabbit IgG (1:5000 dilution) for $1 \mathrm{~h}$ at room temperature. The target protein was detected using enhanced chemiluminescence solution (Amersham Pharmacia Biotech, Little Chalfont, Buckinghamshire, England).

\section{Results}

\subsection{Two-Dimensional Electrophoresis and Protein Analysis}

Moderate differences were observed in the sputum protein profiles between patients with COPD and AECOPD (Figure 1). There were no increases in low-molecularweight proteins in sputum from patients with AECOPD, suggesting there were no factors enhancing the proteolytic degradation of sputum in patients with AECOPD.

Forty-nine spots with expression differences greater than two-fold between sputum from patients with COPD and AECOPD were selected for analysis (Table 2). Using LC/MSD Trap XCT MS after tryptic digestion, we

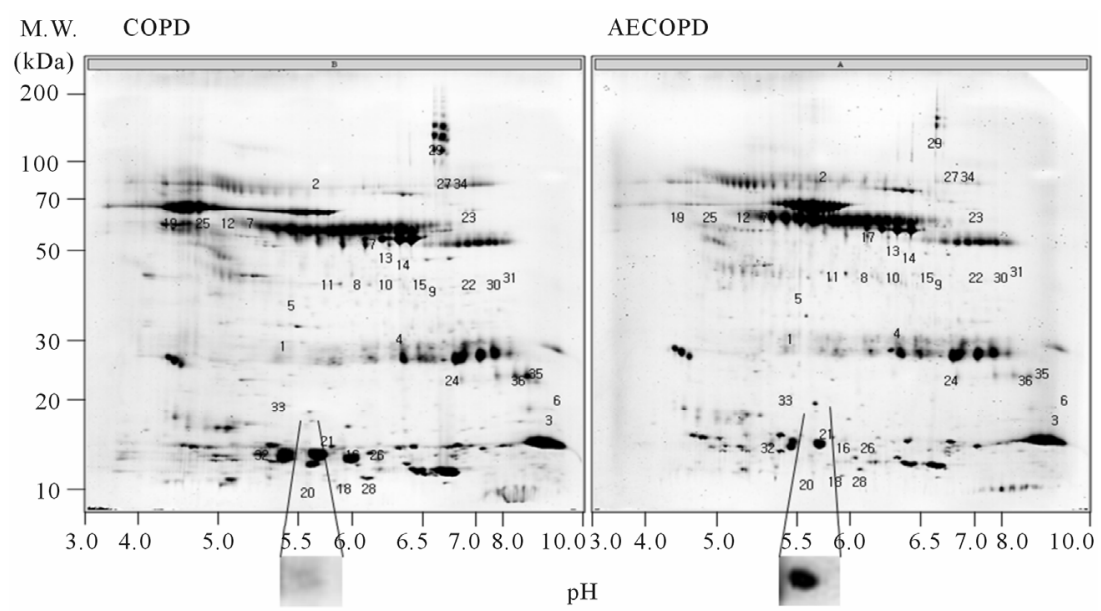

Figure 1. Two-dimensional electrophoresis of pooled sputum proteins obtained from subjects with COPD (n=6, left) and AECOPD ( $n=6$, right). Protein spots identified by LC-MS are numbered. The expression of cyclophilin B is shown in the box. 
Table 2. List of proteins found differentially expressed between patients with COPD and AECOPD.

\begin{tabular}{|c|c|c|c|c|c|c|c|}
\hline \multirow[t]{2}{*}{ NO } & \multirow[t]{2}{*}{ Protein name } & \multirow[t]{2}{*}{ Accession No } & \multirow[t]{2}{*}{ Determined sequence } & \multirow{2}{*}{ MW (kDa)/PI } & \multirow{2}{*}{$\begin{array}{c}\text { Relative intensity } \\
\text { AECOPD }\end{array}$} & \multicolumn{2}{|c|}{$\begin{array}{c}\text { Ratio }^{* *} \\
\text { (ACOPD/COPD) }\end{array}$} \\
\hline & & & & & & \multicolumn{2}{|c|}{ COPD } \\
\hline 1 & keratin 10 & 21961605 & $\begin{array}{l}\text { K. GSLGGGFSSGGFSGGS } \\
\text { FSR.G }\end{array}$ & $59 / 5.1$ & 0.26 & 0.06 & 4.72914 \\
\hline 2 & lactoferrin & 187122 & R. DGAGDVAFIR.E & $82 / 8.5$ & 0.92 & 0.2 & 4.59823 \\
\hline 3 & calpain-like protease CAPN10b & 10503939 & R. AGRGATPAR.E & $60 / 8.4$ & 0.14 & 0.03 & 4.11015 \\
\hline 4 & fibrinogen gamma chain & 182439 & R. IMLEEIMK.Y & $50 / 5.6$ & 0.52 & 0.14 & 3.84717 \\
\hline 5 & fibrin beta & 223002 & R. SILENLR.S & $51 / 8.0$ & 0.08 & 0.02 & 3.75064 \\
\hline 6 & transferrin & 553788 & K. DSGFQMNQLR.G & $55 / 6.0$ & 0.23 & 0.06 & 3.66165 \\
\hline 7 & Ig alpha-2 chain $\mathrm{C}$ region & 87783 & K. YLTWASR.Q & $24 / 5.6$ & 0.79 & 0.24 & 3.31838 \\
\hline 8 & actin, cytoplasmic 2 & 4501887 & K. AGFAGDDAPR.A & $42 / 5.3$ & 0.04 & 0.01 & 3.29507 \\
\hline 9 & keratin 1 & 11935049 & K.SEITELRR.N & $66 / 8.2$ & 0.13 & 0.04 & 3.11773 \\
\hline 10 & $\begin{array}{c}\text { keratin } 10 \text { (epidermolytic } \\
\text { hyperkeratosis) } \\
\text { chain A, cyclophilin B }\end{array}$ & 119581085 & $\begin{array}{l}\text { K. GSLGGGFSSGGFSGGS } \\
\text { FSR.G }\end{array}$ & $63 / 5.1$ & 0.12 & 0.04 & 3.11602 \\
\hline 11 & $\begin{array}{l}\text { complexed with } \\
\text { (d-(Cholinylester)ser8) }\end{array}$ & 1310882 & K. VLEGMEVVR.K & $20 / 9.1$ & 0.29 & 0.09 & 3.03532 \\
\hline 12 & Ig alpha- 2 chain $\mathrm{C}$ region & 87783 & K. YLTWASR.Q & $24 / 5.6$ & 0.47 & 0.16 & 2.94305 \\
\hline 13 & myosin- 9 & 12667788 & R. VVFQEFR.Q & $227 / 5.5$ & 0.05 & 0.02 & 2.72328 \\
\hline 14 & $\begin{array}{l}\text { rab GDP dissociation inhibitor } \\
\text { beta isoform } 1\end{array}$ & 6598323 & K. MLLYTEVTR.Y & $51 / 6.1$ & 0.05 & 0.02 & 2.72328 \\
\hline 15 & $\begin{array}{c}\text { chain } \mathrm{A} \text {, heat-shock } 70 \mathrm{kd} \\
\text { protein } 42 \mathrm{kd} \text { atpase } \\
\text { N-terminal domain }\end{array}$ & 6729803 & K. LLQDFFNGR.D & $42 / 6.7$ & 0.06 & 0.02 & 2.67306 \\
\hline \multicolumn{3}{|c|}{ Proteins Increased in COPD versus AECOPD } & & & & \multicolumn{2}{|c|}{$\begin{array}{c}\text { Ratio }^{* *} \\
\text { (COPD/AECOPD) }\end{array}$} \\
\hline 16 & zinc finger protein 570 & 21389599 & R. QHAHLAHHQR.I & $64 / 8.6$ & 0.04 & 1.38 & 37.7557 \\
\hline 17 & $\begin{array}{l}\text { chain } \mathrm{A} \text {, structure solution and } \\
\text { refinement of the recombinant } \\
\text { human salivary amylase }\end{array}$ & 14719766 & K. IYVSDDGK.A & $56 / 6.2$ & 0.16 & 0.73 & 4.45456 \\
\hline 19 & myosin-9 & 12667788 & R. IMGIPEEEQMGLLR.V & $226 / 5.5$ & 0.05 & 0.24 & 4.3635 \\
\hline 20 & actin binding protein $\mathrm{ABP} 620$ & 5821434 & K. LMALGPIR.L & $623 / 5.3$ & 0.03 & 0.13 & 4.30539 \\
\hline 21 & neuron navigator 2 isoform 2 & 38044282 & K. QQQQQPQK.Q & $263 / 9.5$ & 0.06 & 0.26 & 4.24116 \\
\hline 22 & DIP2B protein & 38014007 & K. TDEIGEICVSSR.T & $101 / 7.1$ & 0.01 & 0.05 & 4.0934 \\
\hline 23 & hCG32657, isoform CRA_g & 119591609 & $\begin{array}{l}\text { K. QSCAAAGSPAVL } \\
\text { GEGR.R }\end{array}$ & $63 / 8.6$ & 0.02 & 0.1 & 3.97971 \\
\hline 24 & proapolipoprotein & 178775 & K. AKPALEDLR.Q & $29 / 5.5$ & 0.02 & 0.07 & 3.45851 \\
\hline 25 & plectin isoform $1 \mathrm{~g}$ & 41322914 & K. GHLSGLAKR.A & $518 / 5.6$ & 0.18 & 0.6 & 3.41069 \\
\hline 26 & $\begin{array}{c}\text { chain A, X-ray crystal } \\
\text { structure of canine } \\
\text { myeloperoxidase at } 3 \text { angstroms }\end{array}$ & 494394 & R. AVSNEIVR.F & $12 / 5.8$ & 0.05 & 0.17 & 3.27962 \\
\hline 27 & lactoferrin & 187122 & K. DSAIGFSR.V & $80 / 8.5$ & 0.05 & 0.14 & 3.03217 \\
\hline 28 & keratin 10 & 186629 & K. SEITELRR.N & $40 / 4.7$ & 0.18 & 0.5 & 2.81186 \\
\hline 29 & KRT9 protein & 113197968 & R. IKFEMEQNLR.Q & $48 / 4.8$ & 0.08 & 0.22 & 2.77102 \\
\hline 30 & $\begin{array}{l}\text { heterogeneous nuclear } \\
\text { ribonucleoproteins A2/B1 } \\
\text { isoform A2 }\end{array}$ & 4504447 & K. AQYEDIAQK.S & $36 / 8.7$ & 0.01 & 0.04 & 2.6475 \\
\hline 31 & keratin 1 & 11935049 & R. GGGGNFGPGPGSNFR.G & $66 / 8.2$ & 0.01 & 0.04 & 2.6475 \\
\hline 32 & $\begin{array}{l}\text { chain A, crystal structure of the } \\
\text { mrp14 complexed with chaps }\end{array}$ & 20150229 & K. DLQNFLK.K & $13 / 5.7$ & 0.21 & 0.54 & 2.54096 \\
\hline 33 & cytochrome P450 4X1 & 29837648 & $\begin{array}{l}\text { R. AFPFWIGPFQAFFCIY } \\
\text { DPDYAK.T }\end{array}$ & $59 / 8.7$ & 0.02 & 0.05 & 2.34272 \\
\hline 34 & $\begin{array}{l}\text { chain A, crystal structure of a } \\
\text { domain-opened mutant }\end{array}$ & 20151211 & K. DSAIGFSR.V & $38 / 9.0$ & 0.09 & 0.22 & 2.33038 \\
\hline 35 & zinc finger protein 334 & 54114904 & K. TSLTRHR.R & $77 / 9.3$ & 0.23 & 0.51 & 2.21493 \\
\hline 36 & zinc finger protein ZNF222 & 6118381 & K. CEDCGKR.Y & $54 / 9.0$ & 0.23 & 0.51 & 2.21493 \\
\hline
\end{tabular}


identified 15 proteins with increased expression in patients with AECOPD and 21 proteins with increased expression in patients with COPD.

Calpain-like protease (CAPN10b), cyclophilin B, Rab GDP dissociation inhibitor, and 70-kDa heat-shock protein (HSP) were increased in sputum from patients with AECOPD compared with COPD. By contrast, lactoferrin, DIP2B, proapolipoprotein, and actin binding protein were increased in patients with COPD compared with AECOPD.

\subsection{Western Blotting for Cyclophilin B in Sputum}

To investigate whether cyclophilin B expression was altered in sputum (Figure 2), we performed Western blot analysis of sputum obtained from similar subjects with AECOPD $(n=4)$ and COPD $(n=4)$ using an antibody specific for cyclophilin B. All patients with AECOPD expressed the protein in sputum, while the protein was not expressed in sputum from patients with COPD.

\section{Discussion}

In this study, we identified inflammation-related proteins that were increased in sputum from patients with AECOPD. Although the roles of these proteins are unknown, their possible use as biomarkers of AECOPD deserves study.

Cyclophilin B is a cyclosporine-binding protein expressed mainly within the endoplasmic reticulum. Cyclophilin B also binds to lymphocytes [13] and may regulate cyclosporine-mediated immunosuppression. We could not identify the mechanism underlying the increased level of cyclophilin B in patients with AECOPD. Therefore, cyclophilin B may be involved in the development of AECOPD or may be an end product. Similar to Creactive protein, an inflammatory marker in COPD [14], cyclophilin B may be a marker of inflammation in patients with AECOPD. An elevated cyclophilin B level in AECOPD was verified by Western blot analysis of sputum.

Calpains are calcium-regulated proteases involved in cellular functions, including muscle proteolysis in cytoskeletal remodeling and signal transduction [15]. The calpain protein level on Western blots did not differ between patients with AECOPD and COPD (data not

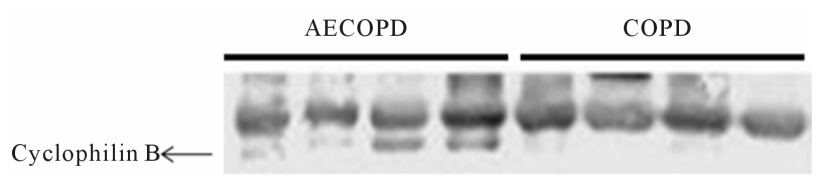

Figure 2. Western blot of cyclophilin B. The 21-kDa cyclophilin $B$ band (arrow) was detected in all patients with AECOPD $(n=4)$, but rarely in patients with COPD $(n=4)$. shown). This suggests that calpains are not important in exacerbation of COPD. The 70-kDa HSP was increased in patients with AECOPD. This can be explained by stress and inflammation in the lung caused by infection during AECOPD [16]. The 70-kDa HSP protein is likely an end product of AECOPD.

The majority of cells in sputum during the acute exacerbations were neutrophils, with a mean differential of $91 \%$. Neutrophils decreased to $65 \%$ by 6 weeks after the acute exacerbation, suggesting that the proteomic differences seen in the present study depend on neutrophil proteins. However, the proteomic differences between an acute exacerbation and stable COPD seen in this study do not seem to depend on neutrophil proteins because the identified proteins were completely different from those seen in a proteomic study using whole human neutrophils $[17,18]$. The proteomic differences identified in our study should be compared with the proteomic differences between "activated" and "stable" neutrophils to determine whether activated neutrophils are a major determinant of our findings. Avram et al. [19] showed that lactoferrin and vimentin are major tyrosyl proteins in neutrophils activated by phorbol myristate acetate or tissue necrosis factor- $\alpha$ (TNF- $\alpha$ ). Therefore, we postulate that our results are related to proteins other than those produced by activated neutrophils.

One limitation of our study is the cause of AECOPD. In this study, the most common cause of AECOPD was infection [1]. The proteomic results may reflect differences between infected and non-infected lung. Second, we could not verify the transcription or translation of the identified proteins in lung tissues because we could not obtain lung tissue samples from the patients with AECOPD. Third, pooled sputum, not individual sputum samples, was used for the proteomics study because individual samples do not contain sufficient protein. This made it difficult to interpret differences in protein expression between patients with COPD and AECOPD. If a specific protein were significantly increased in a single patient with AECOPD, this protein may not also be elevated in the pooled sample.

In conclusion, the proteomic analysis of sputum suggests that changes in the expression of various proteins are associated with the development of AECOPD.

\section{Acknowledgements}

This work was supported by grants from the Korea Health 21 R\&D Project, Ministry of Health, Welfare, and Family Affairs, Republic of Korea (A010249, A090548, and A030003).

\section{REFERENCES}

[1] K. F. Rabe, S. Hurd, A. Anzueto, P. J. Barnes, S. A. Buist, 
P. Calverley, Y. Fukuchi, C. Jenkins, R. Rodriguez-Roisin, C. van Weel and J. Zielinski, "Global Strategy for the Diagnosis, Management, and Prevention of Chronic Obstructive Pulmonary Disease: GOLD Executive Summary," American Journal of Respiratory \& Critical Care Medicine, Vol. 176, No. 6, 2007, pp. 532-555. doi:10.1164/rccm.200703-456SO

[2] K. R. Chapman, D. M. Mannino, J. B. Soriano, P. A. Vermeire, A. S. Buist, M. J. Thun, C. Connell, A. Jemal, T. A. Lee, M. Miravitlles, S. Aldington and R. Beasley, "Epidemiology and Costs of Chronic Obstructive Pulmonary Disease," European Respiratory Journal, Vol. 27, No. 1, 2006, pp. 188-207. doi:10.1183/09031936.06.00024505

[3] D. S. Kim, Y. S. Kim, K. S. Jung, J. H. Chang, C. M. Lim, J. H. Lee, S. T. Uh, J. J. Shim and W. J. Lew, "Prevalence of Chronic Obstructive Pulmonary Disease in Korea: A Population-Based Spirometry Survey," American Journal of Respiratory \& Critical Care Medicine, Vol. 172, No. 7, 2005, pp. 842-847. doi:10.1164/rccm.200502-259OC

[4] S. P. Patil, J. A. Krishnan, N. Lechtzin and G. B. Diette, "In-Hospital Mortality Following Acute Exacerbations of Chronic Obstructive Pulmonary Disease," Archives of Internal Medicine, Vol. 163, No. 10, 2003, pp. 1180-1186. doi:10.1001/archinte.163.10.1180

[5] C. Ai-Ping, K. H. Lee and T. K. Lim, "In-Hospital and 5-Year Mortality of Patients Treated in the ICU for Acute Exacerbation of COPD: A Retrospective Study," Chest, Vol. 128, No. 2, 2005, pp. 518-524. doi:10.1378/chest.128.2.518

[6] J. Berkius, T. Nolin, C. Mardh, G. Karlstrom and S. M. Walther, "Characteristics and Long-Term Outcome of Acute Exacerbations in Chronic Obstructive Pulmonary Disease: An Analysis of Cases in the Swedish Intensive Care Registry during 2002-2006," Acta Anaesthesiologica Scandinavica, Vol. 52, No. 6, 2008, pp. 759-765. doi:10.1111/j.1399-6576.2008.01632.x

[7] M. Cazzola, W. MacNee, F. J. Martinez, K. F. Rabe, L. G. Franciosi, P. J. Barnes, V. Brusasco, P. S. Burge, P. M. Calverley, B. R. Celli, P. W. Jones, D. A. Mahler, B. Make, M. Miravitlles, C. P. Page, P. Palange, D. Parr, M. Pistolesi, S. I. Rennard, M. P. R. Van Molken, R. Stockley, S. D. Sullivan, J. A. Wedzicha and E. F. Wouters, "Outcomes for COPD Pharmacological Trials: From Lung Function to Biomarkers," European Respiratory Journal, Vol. 31, No. 2, 2008, pp. 416-469. doi:10.1183/09031936.00099306

[8] D. A. Lomas, E. K. Silverman, L. D. Edwards, N. W. Locantore, B. E. Miller, D. H. Horstman and R. TalSinger, "Serum Surfactant Protein D Is Steroid Sensitive and Associated with Exacerbations of COPD," European Respiratory Journal, Vol. 34, No. 1, 2009, pp. 95-102. doi:10.1183/09031936.00156508

[9] B. Magi, L. Bini, M. G. Perari, A. Fossi, J. C. Sanchez, D. Hochstrasser, S. Paesano, R. Raggiaschi, A. Santucci, V. Pallini and P. Rottoli, "Bronchoalveolar Lavage Fluid Protein Composition in Patients with Sarcoidosis and Idiopathic Pulmonary Fibrosis: A Two-Dimensional Electrophoretic Study," Electrophoresis, Vol. 23, No. 19, 2002, pp. 3434-3444.
doi:10.1002/1522-2683(200210)23:19<3434::AID-ELPS 3434>3.0.CO;2-R

[10] K. Larsen, J. Malmstrom, M. Wildt, C. Dahlqvist, L. Hansson, G. Marko-Varga, L. Bjermer, A. Scheja and G. Westergren-Thorsson, "Functional and Phenotypical Comparison of Myofibroblasts Derived from Biopsies and Bronchoalveolar Lavage in Mild Asthma and Scleroderma,' Respiratory Research, Vol. 7, No. 1, 2006, p. 11.

[11] M. H. Cha, T. Rhim, K. H. Kim, A. S. Jang, Y. K. Paik and C. S. Park, "Proteomic Identification of Macrophage Migration-Inhibitory Factor upon Exposure to $\mathrm{TiO}_{2}$ Particles," Molecular \& Cellular Proteomics, Vol. 6, No. 1, 2007, pp. 56-63. doi:10.1074/mcp.M600234-MCP200

[12] A. Shevchenko, M. Wilm, O. Vorm and M. Mann, "Mass Spectrometric Sequencing of Proteins Silver-Stained Polyacrylamide Gels," Analytical Chemistry, Vol. 68, No. 5, 1996, pp. 850-858. doi:10.1021/ac950914h

[13] M. Carpentier, F. Allain, M. C. Slomianny, S. Durieux, C. Vanpouille, B. Haendler and G. Spik, "Receptor Type I and Type II Binding Regions and the Peptidyl-Prolyl Isomerase Site of Cyclophilin B Are Required for Enhancement of T-Lymphocyte Adhesion to Fibronectin," Biochemistry, Vol. 41, No. 16, 2002, pp. 5222-5229. doi:10.1021/bi015951j

[14] A. Bircan, M. Gokirmak, O. Kilic, O. Ozturk and A. Akkaya, "C-Reactive Protein Levels in Patients with Chronic Obstructive Pulmonary Disease: Role of Infection," Medical Principles and Practice, Vol. 17, No. 3, 2008, pp. 202-208. doi:159/000117793

[15] Y. Yuan, S. M. Dopheide, C. Ivanidis, H. H. Salem and S. P. Jackson, "Calpain Regulation of Cytoskeletal Signaling Complexes in Von Willebrand Factor-Stimulated Platelets: Distinct Roles for Glycoprotein Ib-V-IX and Glycoprotein IIb-IIIa (Integrin Alpha IIb $_{\text {beta }}$ ) in Von Willebrand Factor-Induced Signal Transduction," Journal of Biological Chemistry, Vol. 272, No. 35, 1997, pp. 21847-21854. doi:10.1074/jbc.272.35.21847

[16] S. P. Ribeiro, J. Villar, G. P. Downey, J. D. Edelson and A. S. Slutsky, "Sodium Arsenite Induces Heat Shock Protein-72 Kilodalton Expression in the Lungs and Protects Rats against Sepsis," Critical Care Medicine, Vol. 22, No. 6, 1994, pp. 922-929. doi:10.1097/00003246-199406000-00008

[17] G. G. Tomazella, I. da Silva, H. J. Laure, J. C. Rosa, R. Chammas, H. G. Wiker, G. A. de Souza and L. J. Greene, "Proteomic Analysis of Total Cellular Proteins of Human Neutrophils," Proteome Science, Vol. 7, No. 8, 2009, p. 32.

[18] M. de Souza Castro, N. M. de Sa, R. P. Gadelha, M. V. de Sousa, C. A. Ricart, B. Fontes and W. Fontes, "Proteome Analysis of Resting Human Neutrophils," Protein and Peptide Letters, Vol. 13, No. 5, 2006, pp. 481-487. doi:10.2174/092986606776819529

[19] D. Avram, E. P. Romijn, E. H. Pap, A. J. Heck and K. W. Wirtz, "Identification of Proteins in Activated Human Neutrophils Susceptible to Tyrosyl Radical Attack: A Proteomic Study Using a Tyrosylating Fluorophore," Proteomics, Vol. 4, No. 8, 2004, pp. 2397-2407. doi:10.1002/pmic.200300755 